\title{
EFECTO DE REMOCIÓN Y RELOCALIZACIÓN DE LEPANTHES ELTOROENSIS STIMSON, DESPUÉS DE UN HURACÁN
}

\author{
Rafael J. Benítez Joubert \& RAymond L. TRemblay ${ }^{1}$ \\ Universidad de Puerto Rico - Humacao, Departamento de Biología - 100 carr. 908, Humacao, Puerto Rico 00791 \\ ${ }^{1}$ Autor para correspondencia: raymond@hpcf.upr.edu
}

La creación de un plan de manejo efectivo es de suma importancia para una especie amenazada de extinción. El huracán Georges (18 de septiembre de 1998) causó grandes cambios en la vegetación de la Sierra de Luquillo, Puerto Rico, a su pasaje por la isla. La orquídea Lepanthes eltoroensis se encuentra amenazada de extinción y está incluida en la lista federal de especies en peligro de extinción desde el 29 de noviembre de 1991. Unos de los efectos ambientales y estocásticos más sobresalientes de este bosque tropical son los huracanes, que causan defoliación y mortandad de gran número de árboles (Walker 1991). Después del huracán Georges, el servicio forestal deseaba reabrir las veredas, pero se encontró con un gran número de plantas de L. eltoroensis creciendo sobre los árboles caídos atra-vesando los senderos. Aprovechamos esta oportunidad para evaluar el efecto de remoción y relocali-zación de plantas como una estrategia para el manejo de esta especie en peligro de extinción, para mejorar su supervivencia después de huracanes futuros. El objetivo de la investigación es disminuir el efecto de la perturbación y maximizar la supervivencia y el éxito reproductivo de la orquídea. Las preguntas principales incluyen: ¿Es viable la relocalización de L. eltoroensis a otros árboles? ¿Cual es el mejor lugar para trasplantarlas, árboles ocupados por orquídeas o árboles no ocupados? En otras palabras, ¿se pueden establecer nuevas poblaciones?

Lepanthes eltoroensis es una pequeña planta epífita que crece sobre varias especies de árboles y palmas. La taza de reproducción de esta especie de Lepanthes es muy baja (Tremblay 1996, Tremblay \& Ackerman 2001), lo cual podría hacer difícil el manejo de la misma. La orquídea está limitada al Bosque Nacional del Caribe conocido localmente como el Yunque, en la Sierra de Luquillo al este de Puerto Rico. La orquídea se encuentra en la asociación de vegetación de bosque enano que está localizada únicamente en las zonas de elevación máxima del bosque (700-1000 m). El área de estudio son las cercanías del Pico El Toro y del Cerro Cacique, en el Bosque Nacional del Caribe. Las poblaciones muestreadas se encuentran a ambos lados a lo largo de aproximadamente $5 \mathrm{~km} \mathrm{de}$ las veredas de Tradewinds y del Cerro El Toro.

Se comenzó en junio del 2000 con la remoción de las plantas que se encontraban creciendo sobre los árboles caídos en ambas veredas. Las plantas fueron relocalizadas y marcadas con un número único. De cada árbol caído se tomó 50\% de las plantas y éstas fueron relocalizadas sobre árboles que tenian una población de L. eltoroensis, el otro $50 \%$ fue relocalizado sobre árboles que no tuvieran plantas, pero cerca de un árbol ocupado. Cada planta fue marcada y clasificada por el tratamiento al cual era sometida. Además se identificaron sin manipulación todas las plantas encontradas en los árboles ya ocupados. En consecuencia, tenemos un diseño experimental no balanceado con tres tratamientos, un grupo control (plantas no removidas y árboles ocupados) y dos grupos experimentales (plantas removidas y relocalizadas sobre árboles ocupados, plantas removidas y relocalizadas sobre árboles no ocupados).

Se realizaron muestreos mensuales durante los primeros cinco meses, luego se realizaron cada 6 meses, hasta completar dos años de muestreo. Aquí se presentan los análisis del efecto de crecimiento de los dos primeros años en los tres tratamientos. Comparamos el crecimiento poblacional entre el primer muestreo y un año después, y luego entre el primero y el segundo año.

Las plantas fueron clasificadas en tres etapas dependiendo de su desarrollo: 1) plántulas: plantas pequeñas que no presentaban pecíolos, 2) juveniles: plantas que presentaban al menos una membrana lepantiforme en el pecíolo, sin ningún tipo de inflorescencia activa o inactiva, y 3 ) adultas: plantas bien desarrolladas que mostraban al menos una inflores- 
cencia activa o inactiva. Los datos recopilados fueron organizados mediante el uso del programa Stat View 4.5. y Excel 2001. Mediante este programa se realizaron los análisis estadísticos generales.

Se utilizó el método de análisis de matrices poblacionales de Lefkovitch de etapas de vida para determinar si las poblaciones son estables. Se utilizó el programa Ramas Ecolab 2.0 para destacar el crecimiento poblacional intrínsico, la elasticidad y la longevidad de las etapas de vida (Akçakaya et al. 1999). El valor instantáneo de crecimiento poblacional, $\lambda$ (lambda), que se obtiene por el análisis de matriz de Lefkovitch, se interpreta de la siguiente manera: cuando $\lambda$ es igual a 1.0 la población es estable, cuando $\lambda$ es mayor o menor que 1.0 la población está creciendo o decreciendo, respectivamente. Se asume que el valor de crecimiento de lambda es determinante y que el efecto estocástico demográfico, ambiental y temporal es minino. El análisis de elasticidad es para determinar cuál de los parámetros demográficos tiene un efecto mayor sobre el crecimiento poblacional. Este análisis puede ayudar a determinar una estrategia de manejo del organismo. La proporción de supervivencia, el cambio de etapas y el esfuerzo reproductivo están incluidos en el modelo. El esfuerzo reproductivo (producción de frutos) fue calculado dividiendo el número de frutos producidos cada año entre el número de plantas adultas en el año en curso. Se utilizó el mismo valor reproductivo para todas las poblaciones. Se observó que la supervivencia y el esfuerzo reproductivo están más correlacionados con la etapa de desarrollo de la planta que con su edad (Tremblay 2000, Tremblay \& Hutchings 2003).

Se muestreó un total de 23 poblaciones, con 326 plantas en tres grupos: 209 de control (plantas no manipuladas); 51 removidas y trasladadas a árboles ocupados; 66 removidas y trasladadas a árboles no ocupados. Un total de 14 poblaciones corresponde a árboles ya ocupados con plantas, donde las orquídeas fueron relocalizadas, y 9 poblaciones a árboles que no estaban ocupados por la orquídea.

El valor reproductivo de las plantas del primer año es la mitad del valor del segundo año (número de reclutas $=$ plántulas $/$ número de adultos $)(7 / 196=$ 0.0357 y $12 / 141=0.0851)$. El valor reproductivo es obtenido de forma indirecta, dado que no se atribuye la producción de plántulas a alguna planta adulta en específico (Caswell 2001).

En el primer año, en las plantas que no fueron removidas se obtuvo una $\lambda=0.8942$ (IC 95\%; 0.8237 - 0.9647); en el segundo año se obtuvo una $\lambda=$ 0.9773 (IC 95\%; 0.9158 - 1.0388). En el grupo control se observó un aumento en la razón de crecimiento y supervivencia. Estos datos demuestran que las poblaciones de esta planta se encuentran en disminución a razón de $10.5 \%$ en el primer año y de $2.27 \%$ en el segundo año. En consecuencia, hay un cambio ambiental positivo entre el primer año y el segundo que no se debe a la manipulación de las orquídeas.

En cambio, en el tratamiento de plantas removidas y relocalizadas en árboles ocupados se obtuvo una $\lambda=$ 0.6899 (IC 95\%; 0.5173-0.8625) en el primer año y una $\lambda=0.9232$ (IC 95\%; 0.6569-1.1895) en el segundo año. En este tratamiento se observó una disminución de $31 \%$ en el primer año y de $7.7 \%$ en el segundo año. Finalmente, para las plantas que fueron relocalizadas en árboles que no tenían las orquídeas creciendo, en el primer año se obtuvo una $\lambda=0.8407$ (IC 95\%; 0.7180-0.9634) y en el segundo año una $\lambda=$ 0.9177 (IC 95\%; 0.7761-1.0593). Esto sugiere que las población de orquídeas relocalizadas en árboles no ocupados tienen una reducción poblacional anual de $16 \%$ en el primer año y de $8 \%$ en el segundo año.

En los tres tratamientos el valor mayor del intervalo de confianza de lambda supera el 1.0 en el segundo año, mostrando que el crecimiento poblacional podria ser estable. Esto es contrario a los resultados obtenidos en el primer año, cuando el rango del intervalo de confianza fue menor que uno y, en consecuencia, se demuestra que la pérdida de plantas en los tres tratamientos está disminuyendo.

La esperanza de vida varía para plántulas, juveniles y adultos. En general, la vida de las plántulas es de un año, independientemente del tratamiento o del período de muestreo. Los juveniles duran entre 1 y 6 años, y los adultos entre 3 y 15 años, dependiendo del tiempo y del grupo experimental. En consecuencia, la esperanza de vida de una planta es de 5 a 20 años, con un promedio cerca de 10 años.

El crecimiento de las poblaciones es muy sensible a los valores de probabilidad de supervivencia de los adultos, según el análisis de elasticidad. Por esto, es 
primordial que se investigue cuále son los factores ambientales que afectan la supervivencia y la reproducción de los adultos.

Claramente se observa que tanto en el grupo de control, como en ambos tratamientos experimentales, las poblaciones aparentan estar alcanzando la estabilidad luego de haber sufrido la perturbación del huracán Georges. El mejoramiento en la supervivencia y la estabilidad poblacional en el segundo año está probablemente asociado con crecimiento del dosel y el aumento de humedad.

Comparando el crecimiento poblacional de los dos tratamientos con el del control es claro que la manipulación de las orquídeas es negativa en el primer año, pero después de dos años se observa un crecimiento poblacional estable y similar al control, sugiriendo que la relocalización de estas plantas es viable como mecanismo para aumentar el tamaño poblacional después de un huracán. Las plantas que se quedan sobre árboles caídos en medio de las veredas tienen poca probabilidad de sobrevivir. Este experimento fse inició dos años después del huracán, cuando las plantas todavía vivas sobre los árboles caídos en las veredas eran mayormente adultas grandes o se encontraban en la parte ventral de los árboles no expuestas al sol ni al viento, pero parecían sufrir de escasez de agua por tener las hojas secas.

Con este experimento se demuestra que el establecimiento de nuevas poblaciones es una estrategia viable para la conservación de esta orquídea. En más de un árbol donde se localizó la orquídea se observaron nuevas plántulas. Éstas pueden provenir de la producción de frutos de las plantas presentes o provenir de inmigrantes. La dispersión de las pequeñas semillas en general es poco exitosa aun en sitios muy cercanos (Tremblay \& Ackerman 2001, Tremblay, Kapan \& Ackerman-Mélendez, datos sin publicar). En trabajos futuros será necesario determinar cuál es el efecto directo de un huracán y determinar cuáles son los parámetros ecológicos (ambiente lumínico, humedad, presencia de musgos) que afectan la supervivencia de esta orquídea.

\section{Literatura CitADA}

Akçakaya, H.R., M.A. Burgman \& L.R. Ginzburg. 1999. Applied Population Ecology: Principles and Computer Exercises using Ramas Ecolab 2,0. Sinauer Associates, Inc. Publishers, Sunderland, Massachussets.

Caswell,H. 2001. Matrix Population Models: Construction, Analysis, and Interpretation, 2nd Ed. Sinauer Associates, Inc., Sunderland, Massachussets.

Tremblay, R.L. 1996. Sex in small population and evolutionary processes. Ph.D. University of Puerto Rico, Rio Piedras Campus. p. 136.

Tremblay, R.L. 2000. Plant longevity in four species of Lepanthes (Pleurothallidinae: Orchidaceae). Lindleyana 15: 257-266

Tremblay, R.L. \& J.D. Ackerman. 2001. Gene flow and effective population size in Lepanthes (Orchidaceae): a case for genetic drift. Biol. J. Linnean Soc. 72: 47-62.

Tremblay, R.L. \& M.J. Hutchings. 2003. Population dynamics in orchid conservation: A review of analytical methods, based on the rare species Lepanthes eltoroensis. In K.W. Dixon, S.P. Kell, R.L. Barrett and P.J. Cribb (eds). Orchid Conservation. Natural History publications, Kota Kinabalu, Sabah, Malaysia.

Walker, R.L. 1991. Tree damage and recovery from Hurricane Hugo in Luquillo Experimental Forest, Puerto Rico. Biotropica 23: 379-385.

Rafael J. Benítez Joubert cursa estudios en la Universidad de Puerto Rico en Humacao, en el Departamento de Biología. Su campo de preparación es la biología con concentración en Manejo de Vida Silvestre. Su vida como estudiante de las ciencias naturales ha sido variada y rica en experiencias que le han ayudado en su formación como futuro científico. También pudo participar en el desarrollo de la propuesta de investigación para la realización de un inventario de las especies de camarones de los ríos del Bosque Estatal de Los Tres Picachos, en el pueblo de Jayuya. Trabajó como intérprete ambiental para el Fideicomiso de Conservación de Puerto Rico. Cada una de estas experiencias lo han ayudado a consolidar su formación como científico. Como planes futuros espera continuar con la ardua e interminable tarea que es la educación en ciencias naturales. 